nuclear material, the method of its division and whether flagellar movement is the cause or the result of the movement of the organism, are treated impar. tially. Tho chapter on bacterial viruses appears short when viewed against the activity and interest in this field-less than twenty pages excluding illustrations. Many of the illustrations included in the volume are outstanding examples of the advances made in technique, especially with the electron microscope.

The various topics are clearly sub-headed and used in conjunction with the detailed contents, and author and subject indexcs make this a very accossible reference work and augurs well that the completed treatise will be the most significant addition to bacteriological literature for some years. It will also be expensive.

L. B. QURSNeL

\section{GENES AND PROTEINS}

The Molecular Basis of Evolution

By Christian B. Anfinsen. Pp. xiii +228 . (New York: John Wiley and Sons, Inc.; London : Chapman and Hall, Ltd., 1959.) 56s. net.

A $\mathrm{T}$ first glance, some features of this book are A likely to seem a bit disconcerting. At the present time there are three fields of inquiry which have considerable claims to be considered, both particularly active and peculiarly important for general biology : one is the evolutionary process ; the other two, which are closely connected, are the sub-structure of genes, and the configuration of the protein molecule. Dr. Anfinsen seems to be claiming to have gathered all three together into the confines of a comparatively small book. Its dust-cover states that he "regards the evolutionary process as the integrated form of genetics and protein chemistry". Unless the word 'genctics', which is a notoriously elastic one, is here taken to include such matters as natural selection, mutation, species divergence and so on, this way of regarding evolution would eertainly seem to be a bad case of Hamlet without the Prince of Denmark.

However, it would be a pity to tako these first impressions too seriously. $\Lambda$ part from reproducing a few well-known figures from a book by G. G. Simpson in the first chapter, and giving a short outline of elementary geneties in the second, the author in fact pays little attention to the subject of evolution. What he has actually produced is a summary of recent work on the relation between the sub-structure of the genes and the proteins which they specify. Most of this account follows the lines which are already becoming recognized as orthodox. For example, in the description of studies of the mechanism of chromosome duplication with the aid of radioactive labels, Anfinsen describes the work of Taylor and his associates, in which the chromosomes did what they had been expected to do, but does not mention that of Plaut and Mazia, who came to different conclusions, although he does add a footnote concerning the results of La Cour and Pele, which also differed from those of Taylor.

The writing in this part of the book is rather slapdash and not very accurate. For example, in discussing Taylor's work on chromosomo duplication on page 59 the author writes: "In an occasional 'second generation' pair of chromosomes, individual sister chromatids were labelled for only part of their length .... and in such cases the corresponding portion of the other chromatid showed radioactivity. This behaviour is to be expected for crossing-over and resembles the cytological observations that have been made for the chromosomes of other specios (e.g. the giant salivary gland chromosomes of Drosophila)". Actually the situation is that when erossing-over occurred in Taylor's chromosomes, and a chromatid was found to be labelled for only part of its length, the corresponding part of the sister chromatid did not show radioactivity. Moreover, no phenomena comparable to crossing-over occur in the giant salivary gland chromosomes of Drosophila. Again, to give another example, on p. 88 Anfinsen writes: "As we discussed in connection with the 'lozenge' genes of Drosophila (Chapter 2), three closely linked genetic loci all appear to be part of the same functional unit since crosses betwoen double heterozygotes bearing both mutant loci on the same strand of the chromosome duplex (i.e. in the cis arrangement) produced wild-type recombinants, wheroas crosses between double heterozygotes in the trans arrangement did not". This sentence suggests a state of complete confusion. In the first place the phrase 'chromosome duplex' is normally used to refer to the two holically twisted strands which together make up the deoxyribonucleic acid molecule ; and the point at issue is not whether the mutant loei are on the same or different strands in such a duplex, but whother they are on the same or different chromosomes. Then the well-known 'cis-trans eriterion', to which Anfinsen is referring, does not turn on the nature of the recombinants which may be produced by crossing the doublo heterozygotes, but on the simple fact whether the double heterozygote itsolf shows the mutant character or not. Anfinsen actually describes this quite correctly in Chaptor 2. Presumably the confusion that has arisen in the passage quoted was due simply to some lapse of attontion.

It is when we pass from the more genetical parts of the book to the more chemical sections that its true value begins to emerge. Anfinsen is himself a protein chemist, and his handling of the chemical aspects of his subject is much more confident than that of the genetical material and, at least to a genetical reader, carries much more conviction. Ho provides an admirably clear account of rocent work on the analysis of the sequence of amino-acids in various proteins, and of attempts to unravel their secondary and tertiary structures. This is illustrated with a large number of very clear diagrams. It will undoubtedly be extromely useful and suggestive to many biologists who are interested in this topic without being expert in it. Thus, in spite of certain inadequacies, therefore, his book has very real value.

\section{H. WaDDingtoN}

\section{GENETIC ANTHROPOLOGY}

\section{The Mothers}

By Robert Briffault. Abridged, with an Introduction by Gordon Rattray Taylor. Pp. 451. (London : George Allen and Unwin, Ltd., 1959.) 36s. net.

THF re-publication of "The Mothers", reduced from more than two thousand pages to less than fivo hundred, is intended to mako it available to "the maximum possible publie". It is doubtful, however, whether any great interest in it will be arouser arnong social scientists, except as an example of a 